\title{
Evaluation of thyroid function status in polycystic ovary syndrome
}

\author{
M Shareefa ${ }^{1}$, Syeda Sobia Harmain ${ }^{2 *}$, Aruna BMK ${ }^{3}$
}

${ }^{1}$ Assistant Professor, ${ }^{2}$ P.G Student, ${ }^{3}$ Professor \& HOD, Department Of Physiology, Kakatiya Medical College, Warangal, Telangana, INDIA.

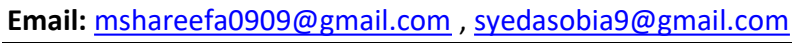

Abstract Background: Polycystic ovary syndrome (PCOS) is the most common endocrinopathy seen in reproductive age women. Recent literature suggests an increase in the incidence of thyroid disorders in females with polycystic ovary syndrome. The aim of this study is to evaluate the occurrence of thyroid dysfunction in subjects with polycystic ovarian syndrome as compared to controls of same age group. The study was a case control study conducted on 90 women, in whom 60 women were diagnosed with PCOS euthyroid and PCOS hypothyroid each and 30 normal healthy women with regular menstrual cycles as the control group within the age group of 20 to 40 years. The study was conducted at the department of Physiology, Kakatiya medical college, Warangal. The study revealed that the thyroid dysfunction was observed in the PCOS groups when compared to the control group. The PCOS hypothyroid women had significantly increased levels of TSH levels when compared to the PCOS euthyroid and control women. The T3 levels were significantly reduced in the PCOS hypothyroid women when compared to PCOS euthyroid and control groups. T4 levels were similar in all the groups. The FSH levels did not show any significant difference between the PCOS euthyroid and PCOS hypothyroid groups, but LH levels showed statistically significant difference between the PCOS euthyroid and PCOS hypothyroid groups. There was an association between the PCOS and the thyroid dysfunction as the TSH levels of the PCOS euthyroid were significantly higher than the control groups and very high in the PCOS hypothyroid groups.

Key Words: Euthyroid, FSH, Hypothyroidism, Polycystic ovarian syndrome, LH

*Address for Correspondence:

Dr Syeda Sobia Harmain, P.G Student, Department of Physiology, Kakatiya Medical College, Warangal, Telangana, INDIA.

Email: syedasobia9@gmail.com

Received Date: 08/04/2020 Revised Date: 10/06/2020 Accepted Date: 05/07/2020

DOI: $\underline{\text { https://doi.org/10.26611/1031522 }}$

This work is licensed under a Creative Commons Attribution-NonCommercial 4.0 International License. $(\boldsymbol{C c})$ EY-NC

\begin{tabular}{|l|l|}
\hline \multicolumn{2}{|c|}{ Access this article online } \\
\hline Quick Response Code: & Website: \\
\hline & www.medpulse.in \\
\hline & \\
\hline
\end{tabular}

\section{INTRODUCTION}

Polycystic ovarian syndrome (PCOS) was first reported by Stein and Levebthal in $1935^{1}$. It is a most common endocrine disorder in the reproductive age group women. PCOS is characterized by menstrual irregularities and endocrine irregularities which results in the anovulation, infertility, and hyperandrogenism. The most common endocrine irregularities seen in PCOS are Insuline resistance (IR) and hyper androgenism. The prevalence of PCOS in the reproductive age women was 8 to $12 \%$ according to the Rotterdam criteria and recently the prevalence is raised to $18 \%{ }^{2,3}$. Thyroid disorders are the most common endocrine disorder globally. The etiopathogenesis of the PCOS and the hypothyroidism are completely different but are associated with menstrual disturbances' and infertility ${ }^{4}, 5$. Thyroid disorders are commonly observed in PCOS subjects especially hypothyroidism, in which the thyrotropin releasing hormone (TRH) raises and leads to altered follicle stimulating hormone (FSH)/luteinizing hormone (LH) ratio and raised dehydroepiandrosterone (DHEAS) levels. Raised thyroid stimulating hormone (TSH) leads to stimulation of FSH receptors. ${ }^{6}$ Thyroid hormonal changes cause cystic ovarian changes with raised ovarian mass ${ }^{7}$. Few studies reported that the thyroid disorders are more common in women with PCOS when compared to the 
normal population ${ }^{8-10}$. This may be due to some common factors predisposing an individual to both disorders or may be due to unestablished pathophysiological connection between the two disorders. There is limited data available regarding the prevalence of hypothyroidism and thyroid dysfunction in patients with PCOS especially in South India. Hence, the present study was aimed to evaluate the occurrence of thyroid dysfunction in subjects with polycystic ovarian syndrome as compared to controls of same age group. The aim of this study is to evaluate the occurrence of thyroid dysfunction in subjects with polycystic ovarian syndrome as compared to controls of same age group.

\section{MATERIALS AND METHODS}

The present study was a case control study conducted on 90 women in which, 60 women were diagnosed with PCOS and 30 normal healthy women with regular menstrual cycles as the control group within the age group of 20 to 40 years. The study was carried out from January 2018 to May 2019 (15 months). The study was conducted at the department of Physiology, Kakatiya medical college, Warangal in collaboration with Obstetrics, gynaecology, infertility clinics at Kakatiya medical college/ hospital, Warangal.

Inclusion criteria: The subjects who were already diagnosed (by Rotterdam criteria) with PCOS as case group and normal healthy subjects with regular menstrual cycle as control group who were within the age group of $20-40$ years were included in the study.

Exclusion criteria: The subjects with known history of any systemic diseases which affects the hormones, subjects who are on medication which may affect the hormones, the subjects who were on the oral contraceptive pills, the pregnant women, lactating women and also the women with the recent history of abortion were excluded from the study.

The subjects were recruited after obtaining a complete medical and surgical history including menstrual history, the age of onset of menarche, family history of PCOS, and history of hirsutism, acne, alopecia, infertility and also about the history of last pregnancy and/or abortion. Any histories of headaches or blurred vision any signs or symptoms of thyroid dysfunction including acne, hirsutism, deepening of voice, and increase in muscle mass were also recorded. The subjects present age and the age of attainment of menarche were noted in all the subjects. The height, weight were measured and the body mass index (BMI) was calculated and recorded. In the present study the subjects were categorized into 3 groups. All the subjects were observed investigated for serum thyroid stimulating hormone (TSH) and T3 and T4 levels. The normal TSH level was considered as $0.5-4.5 \mathrm{mIU} / \mathrm{L}$ and the normal freeT3 and T4 levels were considered as 2.4$4.2 \mathrm{ng} / \mathrm{ml}$ and $0.7-1.24 \mathrm{ng} / \mathrm{dl}$ respectively. If thyroid is in normal level, those are included in control group and PCOS subjects were again classified into 2 groups based on thyroid hormone levels as euthyroid and PCOS hypothyroid.

\begin{tabular}{|ccc}
\multicolumn{3}{c}{ Table 1: Showing the distribution of sample in the study } \\
\hline Group & Subject type & Number of subjects \\
\hline Group 1 & Control & 30 \\
Group 2 & PCOS Euthyroid & 30 \\
Group 3 & PCOS Hypothyroid & 30 \\
\hline
\end{tabular}

About $4 \mathrm{ml}$ of fasting venous blood was collected in aseptic conditions from all the subjects into serum vacutainer (Red cap) for thyroid profile. The samples were stored in refrigerator at 2 to $8^{\circ} \mathrm{C}$. The samples were centrifuged and the serum was separated. The thyroid stimulating hormone (TSH), triiodothyronine T3, thyroxine T4, was estimated by using Chemiluminescence Immunoassay (CLIA) using Siemens adiva centaur XPT immunoassay analyzer, follicle stimulating hormone (FSH) were measured by using automatic Beckman Access 2 Immunoassay System and LH Hormone measured by enzyme-linked immunosorbent assay.

Statistical analysis

The range, mean and standard deviations were calculated for age, height, weight, BMI, age at menarche, T3, T4, TSH and FSH hormones. The data was also processed by using ' $t$ ' test to find out the level of significance between the groups at $95 \% \mathrm{CI}$.

\section{OBSERVATIONS AND RESULTS}

This study includes normal healthy subjects in control group and PCOS subjects in euthyroid and hypothyroid groups. This study is conducted to evaluate the thyroid hormone status along with levels of the FSH, LH and the LH/FSH ratio in the PCOS Euthyroid and PCOS Hypothyroid when compared with healthy controls. The average age at menarche of the control group was $12.03 \pm 0.96$ years with the range of 11 to 14 years, of PCOS euthyroid group was $12.03 \pm 0.80$ years with the range of 11 to 14 years, of the PCOS hypothyroidism group was $12 \pm 0.83$ years with the range of 11 to 14 years. The means of height, weight, BMI, TSH, $\mathrm{T}_{3}, \mathrm{~T}_{4}$, FSH and LH hormones of the control group, PCOS euthyroid group, PCOS hypothyroidism group were recorded in table 2 . The data was processed using ' $\mathrm{t}$ ' test and the level of significance was considered as $\mathrm{P}<0.05$ 
Table 2: Comparison of the hormone levels in all the groups

\begin{tabular}{ccccc}
\hline 1 & Parameters & Control & PCOS Euthyroid & PCOS Hypothyroid \\
\hline 2 & Height (in cm) & $147.9 \pm 7.34$ & $142.86 \pm 7.37$ & $161.76 \pm 8.36$ \\
3 & Weight (in kgs) & $49.33 \pm 6.45$ & $46.8 \pm 8.10$ & $62.16 \pm 4.37$ \\
4 & Age (in years) & $30.56 \pm 3.15$ & $30.33 \pm 3.29$ & $26.26 \pm 3.92$ \\
5 & BMI & $22.48 \pm 3.48$ & $23.06 \pm 4.32$ & $24.02 \pm 1.26$ \\
6 & $\mathrm{TSH}(\mu \mathrm{lU} / \mathrm{ml})$ & $1.76 \pm 0.81$ & $1.86 \pm 0.65$ & $7.09 \pm 2.68$ \\
7 & $\mathrm{~T}_{3}(\mathrm{ng} / \mathrm{dl})$ & $1.17 \pm 0.83$ & $1.20 \pm 0.18$ & $1.10 \pm 0.23$ \\
8 & $\mathrm{~T}_{4}(\mu \mathrm{g} / \mathrm{dl})$ & $8.5 \pm 0.72$ & $9.09 \pm 2.32$ & $8.35 \pm 1.22$ \\
9 & $\mathrm{FSH}(\mathrm{mlU} / \mathrm{ml})$ & $15.49 \pm 2.05$ & $6.22 \pm 1.78$ & $6.26 \pm 1.90$ \\
10 & $\mathrm{LH}(\mathrm{mlU} / \mathrm{ml})$ & $7.8 \pm 1.23$ & $7.93 \pm 4.2$ & $10.98 \pm 4.63$ \\
\hline
\end{tabular}

The $T_{3}$ levels were statistically significantly lower in the control group and PCOS euthyroid groups when compared to the PCOS hypothyroid group. There was no significant difference between the control and PCOS euthyroid group. Significant decrease in the $T_{3}$ levels was observed in the PCOS hypothyroid group when compared to PCOS euthyroid group $(\mathrm{P}=0.03)$ and control group $(\mathrm{P}=03)$. The $\mathrm{T}_{4}$ levels were observed to be similar in all the groups. There was no statistically significant difference among the 3 groups. The TSH levels were observed to be significantly higher in the PCOS hypothyroid group when compared to the control and the PCOS euthyroid groups.

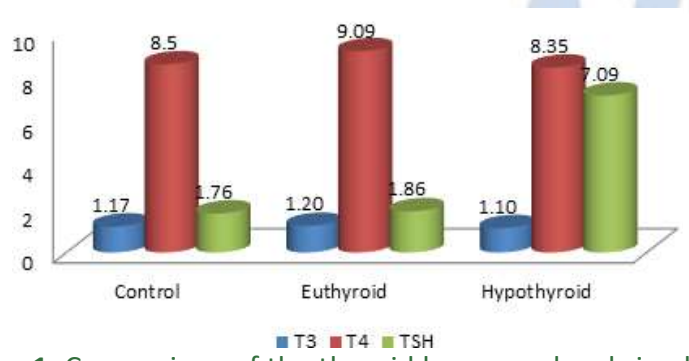

Figure 1: Comparison of the thyroid hormone levels in all the groups

The FSH levels did not show any significant difference between the PCOS euthyroid and PCOS hypothyroid groups $(\mathrm{p}=0.46)$ The mean LH in the PCOS euthyroid, and PCOS hypothyroid groups were $7.93 \pm 4.2 \mathrm{mlU} / \mathrm{ml}$ and $10.98 \pm 4.63 \mathrm{mlU} / \mathrm{ml}$ respectively. Statistically significantly higher levels were observed in PCOS hypothyroid group when compared to PCOS euthyroid group with $\mathrm{p}$ value of 0.0049 .

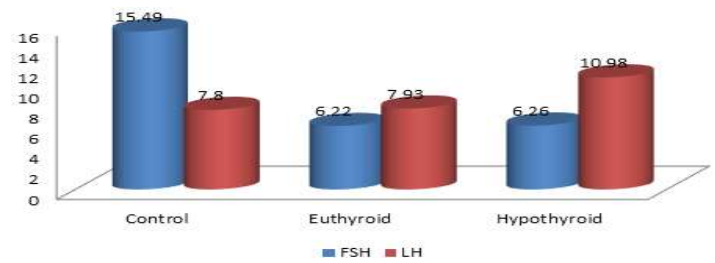

Figure 2: Comparison of the FSHandLH hormone levels in all the groups

\section{DISCUSSION}

Recent literature suggests an increase in the incidence of thyroid disorders in females with polycystic ovary syndrome. A study by Sinha et al.,[8] compared 80 PCOS women with 80 controls and reported significant increase in the prevalence of goiter and subclinical hypothyroidism in PCOS women when compared to the normal control groups. Another study reported that, the prevalence of PCOS women with subclinical hypothyroidism as $11.3 \%^{11}$. In this present study the thyroid function was assessed by measuring the serum thyroid hormone levels in all the 3 groups. The mean age of the women in control group was $30.56 \pm 3.15$ years, in the PCOS euthyroid group was $30.33 \pm 3.29$ years and in the PCOS hypothyroid group was $26.26 \pm 3.92$ years. The mean age is less in the PCOS hypothyroid group as they present early due to menstrual irregularities caused by both hypothyroidism and PCOS. In a study by Kedar et al., ${ }^{7}$ found the mean age of the women in PCOS and control groups were $22.86 \pm 3.5$ years and $24.3 \pm 3.5$ years respectively and found that, the mean age is less in the PCOS group compared to control group as they present early due to menstrual irregularities. The BMI of the PCOS hypothyroid women shows significantly higher values when compared to control groups with $(\mathrm{P}=$ $0.013)$. These results are similar to the others results ${ }^{7,12]}$ Over weight and obesity are commonly observed in both PCOS and hypothyroidism, so there was a significant increase in the BMI in PCOS and hypothyroid groups ${ }^{13}$. In the present study the mean TSH levels in control, PCOS euthyroid and PCOS hypothyroid groups were $1.76 \pm 0.81 \mu \mathrm{U} / \mathrm{ml}, \quad 1.86 \pm 0.65 \mu \mathrm{U} / \mathrm{ml} \quad$ and $7.09 \pm 2.68 \mu \mathrm{U} / \mathrm{ml}$ respectively. The PCOS euthyroid group values were within the normal range but significantly higher than the control group where the $p$ value was 0.001 and the PCOS hypothyroid group was very high compared to the control and the PCOS euthyroid groups. Many studies have been done to find out the association between the TSH and PCOS, but few studies reported an association between the control and PCOS groups as the TSH values were significantly higher in PCOS group compared to control groups ${ }^{8,12,13}$. 
In the present study, the PCOS subjects were divided into 2 groups based on the TSH levels into PCOS euthyroid group and PCOS hypothyroid group and compared the thyroid profile between all there 3 groups and found statistically significant difference between them. In the present study, in all the subjects $T_{3}$ and $T_{4}$ were also estimated along with TSH and the levels were compared between the groups. The mean $\mathrm{T}_{3}$ levels in the control, PCOS euthyroid and PCOS hypothyroid groups were $1.17 \mathrm{ng} / \mathrm{dl}, 1.20 \mathrm{ng} / \mathrm{dl}$ and $1.10 \mathrm{ng} / \mathrm{dl}$ respectively. There was a marked decrease in the $T_{3}$ levels of PCOS hypothyroid group when compared to PCOS euthyroid and control groups these results were in similar with other study by Kedar et al. ${ }^{7}$. As these two studies were done in the Indian population, there was not ethnic variation also, which would be a factor to find the similar results. In the present study the mean $\mathrm{T}_{4}$ levels in the control, PCOS euthyroid and PCOS hypothyroid groups were $8.5 \mathrm{ng} / \mathrm{dl}$, $9.091 \mathrm{ng} / \mathrm{dl}$ and $8.35 \mathrm{ng} / \mathrm{dl}$ respectively. The $\mathrm{T}_{4}$ levels were similar in all the groups and there was no significant difference found among the groups which is coinciding with other studies by Kedar et al.. ${ }^{7}$, and Elslimani et al. ${ }^{14}$, but in contrast with the study by Eldin et al. ${ }^{15}$ where they had reported a significant decrease in the $\mathrm{T}_{4}$ levels $(\mathrm{P}<$ 0.01 ) of the PCOS group when compared to control group and they also found difference in the $\mathrm{T}_{4}$ levels between the PCOS lean and PCOS over weight groups. According to Carvalho et al. ${ }^{16}$ and Schussler et al. ${ }^{17}$ any alterations in the transporter proteins may give rise to altered levels of total $\mathrm{T}_{4}$ levels irrespective of its thyroid status. Thus the lower $\mathrm{T}_{4}$ cannot be explained by isolated thyroid abnormality. There was no significant difference between the levels of FSH in PCOS euthyroid and PCOS hypothyroid groups. The present study results were nearer to the other study by Ramanand SS et al.,[18] who reported the mean FSH levels of PCOS euthyroid and PCOS hypothyroid as $5.70 \pm 1.80 \mathrm{mlU} / \mathrm{ml}$ and $5.32 \pm 1.54 \mathrm{mlU} / \mathrm{ml}$ respectively. The mean $\mathrm{LH}$ levels in PCOS euthyroid and PCOS hypothyroid groups were $7.93 \mathrm{mIU} / \mathrm{ml}$ and $10.98 \mathrm{mIU} / \mathrm{ml}$ respectively. Statistically significant difference was observed between the PCOS euthyroid and PCOS hypothyroid groups $(\mathrm{p}=0.004)$ which is similar to the study by Ramanand et al., [18] who reported the average LH levels in PCOS euthyroid and PCOS hypothyroid as $12.54 \mathrm{mlU} / \mathrm{ml}$ and $10.38 \mathrm{mlU} / \mathrm{ml}$ respectively. The LH/FSH ratio did not show any significant difference between the PCOS euthyroid and PCOS hypothyroid groups.

\section{CONCLUSION}

The present study revealed that the thyroid dysfunction was observed in the PCOS groups when compared to the control group. The PCOS hypothyroid women had significantly increased levels of TSH levels when compared to the PCOS euthyroid and control women. The T3 levels were significantly reduced in the PCOS hypothyroid women when compared to PCOS euthyroid and control groups. T4 levels were similar in all the groups. The FSH levels did not show any significant difference between the PCOS euthyroid and PCOS hypothyroid groups, but LH levels showed statistically significant difference between the PCOS euthyroid and PCOS hypothyroid groups. There was an association between the PCOS and the thyroid dysfunction as the TSH levels of the PCOS euthyroid were significantly higher than the control groups and very high in the PCOS hypothyroid groups. Thus, the physicians should routinely advice the thyroid profile for the PCOS patients and treat the thyroid dysfunction which may help in the management of menstrual irregularities and infertility.

\section{ACKNOWLEDGMENTS}

The authors are thankful to the Kakatiya medical college/Hospital for providing facilities to conduct this study.

\section{REFERENCES}

1. Stein IF, Leventhal ML. Amenorrhea associated with bilateral polycystic ovaries. Am J Obstet Gynecol. 1935(29): 181-191.

2. Mueller A, Schofl C, Dittrich R. Thyroid-stimulating hormone is associated with insulin resistance independently of body mass index and age in women with polycystic ovary syndrome. Human Repro. 2009;24(11):2924-30.

3. Diamanti-Kandarakis E, DunaifA. Insulin resistance and the polycystic ovary syndrome revisited: An update on mechanisms and implications. Endocr Rev. 2012; 33:981-1030

4. Unnikrishnan AG, Kalra S, Sahay RK, Bantwal G, John M, Tewari N. Prevalence of hypothyroidism in adults: An epidemiological study in eight cities of India. Indian $\mathbf{J}$ EndocrinolMetab. 2013;17:647-52.

5. Marwaha RK, Tandon N, Ganie MA, Kanwar R, Sastry A, Garg MK, et al. Status of thyroid function in Indian adults: Two decades after universal salt iodization. J Assoc Physicians India. 2012;60:32- 6.

6. Erel CT, Senturk LM, Kaleli S, Gezer A, Baysal B, Tasan E. Is serum leptin level regulated by thyroid functions, lipid metabolism and insulin resistance in poly cystic ovary syndrome? GynecolEndocrinol. 2003; 17(3):222-3.

7. Kedar KV, Rewatkar MM, Akare MD. Thyroid dysfunction in women with polycystic ovarian syndrome:A comparative study. Int J Reprod Contracept Obstet Gynecol 2019; 8:1943-5.

8. Sinha U, Sinharay K, Saha S, Longkumer TA, Baul SN, $\mathrm{Pal}$ SK. Thyroid disorders in polycystic ovarian syndrome subjects: A tertiary hospital based cross sectional study 
from Eastern India. Indian J EndocrinolMetab 2013; 17:304- 9 .

9. Janssen OE, Mehlmauer N, Hahn S, Offner AH, Gärtner R. High prevalence of autoimmune thyroiditis in patients with polycystic ovary syndrome. Eur J Endocrinol 2004; 150:363-9.

10. Kachuei M, Jafari F, Kachuei A, Keshteli AH. Prevalence of autoimmune thyroiditis in patients with polycystic ovary syndrome. Arch GynecolObstet 2012; 285:853-6.

11. Benetti Pinto CL, Berini Piccolo VR, Garmes HM, TeatinJuliato CR. Subclinical hypothyroidism in young women with polycystic ovary syndrome: An analysis of clinical, hormonal, and metabolic parameters. FertilSteril 2013; 99:588-92.

12. Franks S, Stark J, Hardy K. Follicle dynamics and anovulation in polycystic ovary syndrome. Hum Reprod Update. 2008;14(4):367-78.

13. Moustafa MM, Jamal MY and Al-Janabi RD. Thyroid hormonal changes among women with polycystic ovarian syndrome in Baghdad - a case-control study. F1000Research 2019, 8:669.
14. Fatma Al-zarougElslimani, Mona Elhasi, and MaraiaFaragElmhdwi. The Relation between Hypothyroidism and Polycystic Ovary Syndrome. J. Pharm. Appl. Chem. 2016; 2(3):197-200.

15. Kamal Eldin Ahmed Abdelsalam and Waleed Ibrahim. Relationship between TSH, T4, T3 and Prolactin in overweight and lean Sudanese PCOS Patients. International Journal of Biomedical Research. 2015; 6(02): 108-112.

16. Carvalho GA, Perez CL, Ward LS. The clinical use of thyroid function tests. Arquivosbrasileiros de endocrinologia e metabologia. 2013; 57(3):193-204.

17. Schussler GC. The thyroxine-binding proteins. Thyroid. 2000; 10(2):141-9.

18. Ramanand SJ, Raparti GT, Halasawadekar NR, Ramanand JB, Kumbhar AV, Shah RD. Hypothyroidism in polycystic ovarian syndrome: a comparative study of clinical characteristics, metabolic and hormonal parameters in euthyroid and hypothyroid polycystic ovarian syndrome women. Int $\mathrm{J}$ Reprod Contracept Obstet Gynecol 2016; 5:3181-5.

\section{Source of Support: None Declared Conflict of Interest: None Declared}

Policy for Articles with Open Access:

Authors who publish with MedPulse International Journal of Physiology (Print ISSN: 2550-7613) (Online ISSN: 2636-4565) agree to the following terms: Authors retain copyright and grant the journal right of first publication with the work simultaneously licensed under a Creative Commons Attribution License that allows others to share the work with an acknowledgement of the work's authorship and initial publication in this journal.

Authors are permitted and encouraged to post links to their work online (e.g., in institutional repositories or on their website) prior to and during the submission process, as it can lead to productive exchanges, as well as earlier and greater citation of published work. 